\title{
Endocrine abnormalities in ataxia telangiectasia: findings from a national cohort
}

\author{
Andreea Nissenkorn ${ }^{1,2}$, Yael Levy-Shraga ${ }^{2,3}$, Yonit Banet-Levi ${ }^{4}$, Avishay Lahad ${ }^{5}$, Ifat Sarouk ${ }^{6}$ and Dalit Modan-Moses ${ }^{2,3}$
}

BACKGROUND: Ataxia telangiectasia (AT) is a genetic multisystem disorder, presenting with progressive ataxia, immune deficiency, and propensity toward malignancy. Endocrine abnormalities (growth retardation, reproductive dysfunction, and diabetes) have been described, however detailed information regarding this aspect is lacking. We aimed to characterize endocrine anomalies and growth patterns in a large cohort of AT patients.

METHODS: Retrospective study comprising all 52 patients (aged 2-26.2 y) followed at a national AT Clinic. Anthropometric and laboratory measurements were extracted from the charts. RESULTS: Median height-SDS was already subnormal during infancy, remaining negative throughout follow up to adulthood. Height-SDS was more impaired than weight-SDS up to age $4 y$, thereafter weight-SDS steadily decreased, resulting in progressively lower BMI-SDS. IGF-I-SDS was low $(-1.53 \pm 1.54)$, but did not correlate with height-SDS. Gonadal failure was present in all 13 females older than 10 y but only in one male. Two patients had diabetes and 10 had dyslipidemia. Vitamin D deficiency was observed in $52.2 \%$ of the evaluated patients. CONCLUSION: Our results suggest a primary growth abnormality in AT, rather than secondary to nutritional impairment or disease severity. Sex hormone replacement should be considered for female patients. Vitamin D levels should be followed and supplementation given if needed.

A taxia telangiectasia (AT), is a genetic disorder characterized by progressive cerebellar neurodegeneration, ocular telangiectasias, immunodeficiency, sensitivity to ionizing radiation, and increased predisposition to lymphoid malignancies $(1,2)$. AT is caused by mutations in the ATM gene (HGNC:795), leading to complete absence or impaired function of the ATM protein kinase, a major activator of the cellular response to DNA double-strand breaks (DSBs) (3).

A number of studies $(1,4-13)$ reported endocrine abnormalities in AT patients. However, patient series are mostly small, lacking detailed description of endocrine abnormalities, and outdated. Growth retardation has been repeatedly described in patients with AT $(1,4-6,8,12,14)$, and has been attributed to sinopulmonary infections (4) or to growth hormone or IGF-I deficiency $(8,14)$. However, detailed description of growth patterns in these patients is not available. Several studies reported reproductive dysfunction with infertility, amenorrhea and anovulatory cycles in females, and disrupted spermatogenesis in males, probably due to gonadal failure $(5,6,12,15)$. Insulin resistance and diabetes mellitus have been described in older patients with AT, usually in association with liver dysfunction $(4,6,12,16,17)$. Abnormal histological findings of the pituitary gland have been described in some reports, however these findings have not been correlated with pituitary function $(11,18,19)$. Hypothyroidism has been reported in a single series (4).

The aim of this study was to characterize endocrine anomalies and growth patterns in a large cohort of patients with AT.

\section{RESULTS}

Patients' Characteristics

Fifty-two patients (23 females), aged 2-26.2 y at the time of last evaluation (mean $14.1 \pm 4.9$ ) were included. The diagnosis of AT was established based on mutant ATM in 45 patients, absent ATM on western blot in 7. Forty-three patients were homozygous for the ATM mutation, and two were double heterozygotes. Four patients had a double missense mutation with retained ATM protein and a mild clinical picture (20). All other patients had truncating mutations and a classical severe phenotype. The most prevalent mutations were c.7249del 4 (14 patients), and $\mathrm{c} .103 \mathrm{~T}>\mathrm{C}$ (10 patients).Thirty-one patients were confined to wheel chairs, 18 had present or past malignancies. Nineteen patients were deceased at the time of data collection.

\section{Growth Data}

Forty-seven patients had at least one growth measurement. A total of 433 measurements were available for analysis. Age at last assessment was $14.2 \pm 5.2$ y (range: $2.5-26.3$ ).

Median height-SDS was negative at all ages (Table 1, Figure 1). Height-SDS was already subnormal in infancy, before clinical

\footnotetext{
'Service for Rare Disorders, Pediatric Neurology Unit, The Edmond and Lilly Safra Children's Hospital, Sheba Medical Center, Ramat Gan, Israel; ${ }^{2}$ The Sackler School of Medicine, Tel-Aviv University, Tel-Aviv, Israel; ${ }^{3}$ Pediatric Endocrinology and Diabetes Unit, The Edmond and Lilly Safra Children's Hospital, Sheba Medical Center, Ramat Gan, Israel;

${ }^{4}$ The National Ataxia-Telangiectasia Clinic, The Edmond and Lilly Safra Children's Hospital, Sheba Medical Center, Ramat Gan, Israel; ${ }^{5}$ Division of Pediatric Gastroenterology and Nutrition, Safra Children's Hospital, Sheba Medical Center, Tel-Hashomer, Israel; ${ }^{6}$ Pediatric Pulmonary Unit, The Edmond and Lilly Safra Children's Hospital, Sheba Medical Center, Ramat Gan, Israel. Correspondence: Dalit Modan-Moses (dmodan@sheba.health.gov.il)

Received 27 September 2015; accepted 21 November 2015; advance online publication 9 March 2016. doi:10.1038/pr.2016.19
} 


\section{Articles | Nissenkorn et al.}

onset of disease, and did not further deteriorate thereafter. HeightSDS was more impaired than weight-SDS in infancy. Thereafter, weight-SDS steadily decreased, resulting in a progressively worse BMI-SDS (Table 1, Figure 1).

Table 1. Anthropometric measurements according to age

\begin{tabular}{|c|c|c|c|c|}
\hline $\begin{array}{l}\text { Age, } \\
\text { years }\end{array}$ & $N$ & $\begin{array}{l}\text { Height-SDS } \\
\text { median (IQR })\end{array}$ & $\begin{array}{l}\text { Weight-SDS } \\
\text { median (IQR) }\end{array}$ & $\begin{array}{c}\mathrm{BMI}^{\mathrm{BMDS}}{ }^{\mathrm{b}} \\
\text { median (IQR) }\end{array}$ \\
\hline $0-1$ & 8 & $-0.6(-1.3,0.1)$ & $-0.4(-1.4,0.9)$ & - \\
\hline 1 & 8 & $-1.3(-1.7,0)$ & $-1.5(-1.8,-0.9)$ & - \\
\hline 2 & 8 & $-0.9(-1.3,0.1)$ & $-0.9(-1.8,-0.4)$ & $-0.7(-1.2,0)$ \\
\hline 3 & 8 & $-1.6(-2,-1)$ & $-0.9(-1.7,-0.5)$ & $-0.1(-0.8,1.1)$ \\
\hline 4 & 14 & $-1.2(-1.6,-0.7)$ & $-1.4(-2.6,-0.4)$ & $-1.6(-1.8,0.5)$ \\
\hline 5 & 12 & $-1.5(-1.9,-1.1)$ & $-1.7(-2.3,-0.8)$ & $-0.9(-1.3,0.4)$ \\
\hline 6 & 17 & $-1.5(-2,-0.7)$ & $-1.5(-2.9,-1)$ & $-1.2(-2.2,-0.3)$ \\
\hline 7 & 18 & $-1.6(-2.5,-1.2)$ & $-2.3(-3.9,-1)$ & $-1.3(-3.1,-0.8)$ \\
\hline 8 & 14 & $-2.2(-2.8,-1.5)$ & $-2.7(-3.8,-1.3)$ & $-1.4(-2.3,-0.6)$ \\
\hline 9 & 15 & $-1.7(-2.5,-1)$ & $-1.9(-3.9,-1.2)$ & $-1.8(-2.6,-0.2)$ \\
\hline 10 & 21 & $-1.8(-2.9,-1.1)$ & $-2.3(-3.7,-1.5)$ & $-2.1(-3.5,-0.8)$ \\
\hline 11 & 17 & $-1.6(-2.4,-1.3)$ & $-2(-4.7,-1)$ & $-2(-3.8,-0.7)$ \\
\hline 12 & 16 & $-1.5(-2.1,-1)$ & $-2(-3.5,-1.4)$ & $-1.6(-3.9,-1)$ \\
\hline 13 & 14 & $-1.3(-2,-0.9)$ & $-2.8(-3.5,-1.9)$ & $-3.4(-4.1,-1.8)$ \\
\hline 14 & 12 & $-2.1(-3.1,-0.8)$ & $-4.1(-7.2,-1.7)$ & $-4.7(-6.3,-1.9)$ \\
\hline 15 & 10 & $-1.4(-2.3,-0.9)$ & $-3.4(-5.1,-1.5)$ & $-3.9(-5.2,-2.6)$ \\
\hline 16 & 9 & $-1.3(-2.5,-0.4)$ & $-4.3(-4.9,-0.8)$ & $-4.6(-5.2,-1)$ \\
\hline 17 & 5 & $-1.6(-2.3,-1.4)$ & $-4(-7.6,-1.2)$ & $-8.5(-8.5,-1.6)$ \\
\hline 18 & 5 & $-1.9(-2.3,-0.9)$ & $-3.8(-4.4,-2.3)$ & $-1.8(-3.6,-1.4)$ \\
\hline $19-26$ & 8 & $-0.8(-1.8,-0.1)$ & $-2.5(-5.4,-1)$ & $-2.1(-9.2,-1.2)$ \\
\hline
\end{tabular}

a $Q R$, interquartile range. ${ }^{b} B M I-S D S$ is only available after age $2 y$.
Growth retardation was more prominent in females during later childhood and adolescence (Table 2, Figure 2). There was no influence of type of ATM mutation, ambulation capacity, or a history of malignancy on height-SDS or weight-SDS.

Mean IGF-I-SDS was low $(-1.53 \pm 1.54)$. There was no correlation between IGF-I-SDS and height-SDS $(r=0.09, P=0.6)$, weight-SDS $(r=-0.03, P=0.8)$, or BMI-SDS $(r=-0.19, P=0.3)$.

\section{Gonadal Function}

Gonadotropin levels were available for 36 patients (18 males, 18 females). Among males, 17 had luteinizing hormone (LH), follicle-stimulating hormone (FSH) and testosterone levels appropriate for their age. One patient had mildly elevated $\mathrm{LH}$ and FSH levels with normal testosterone.

Of the female patients, 13 had high levels of LH and FSH (LH $>15 \mathrm{IU} / \mathrm{l}$ and/or FSH levels > $25 \mathrm{IU} / \mathrm{l}$ ) indicating ovarian failure.

All five females with normal gonadotropin levels were less than $10 \mathrm{y}$ old, an age when the pituitary-gonadal axis is naturally repressed and normal gonadotropin levels do not exclude gonadal failure.

Clinically, female patients with elevated gonadotropin levels presented a spectrum: only one patient had complete sexual development with regular periods. This patient carried the double missense mutation with retained ATM protein function. Of the other patients, one had complete sexual development with regular periods followed by secondary amenorrhea, three patients had menarche but data regarding subsequent periods were missing, one patient had partial development of secondary sex signs but primary amenorrhea, and one patient had no signs of puberty on her last evaluation at the age of $19 \mathrm{y}$. Five patients were assessed before $13 \mathrm{y}$ of age and had no signs of puberty at that time, which could still be considered normal for their age; however, their increased gonadotropin

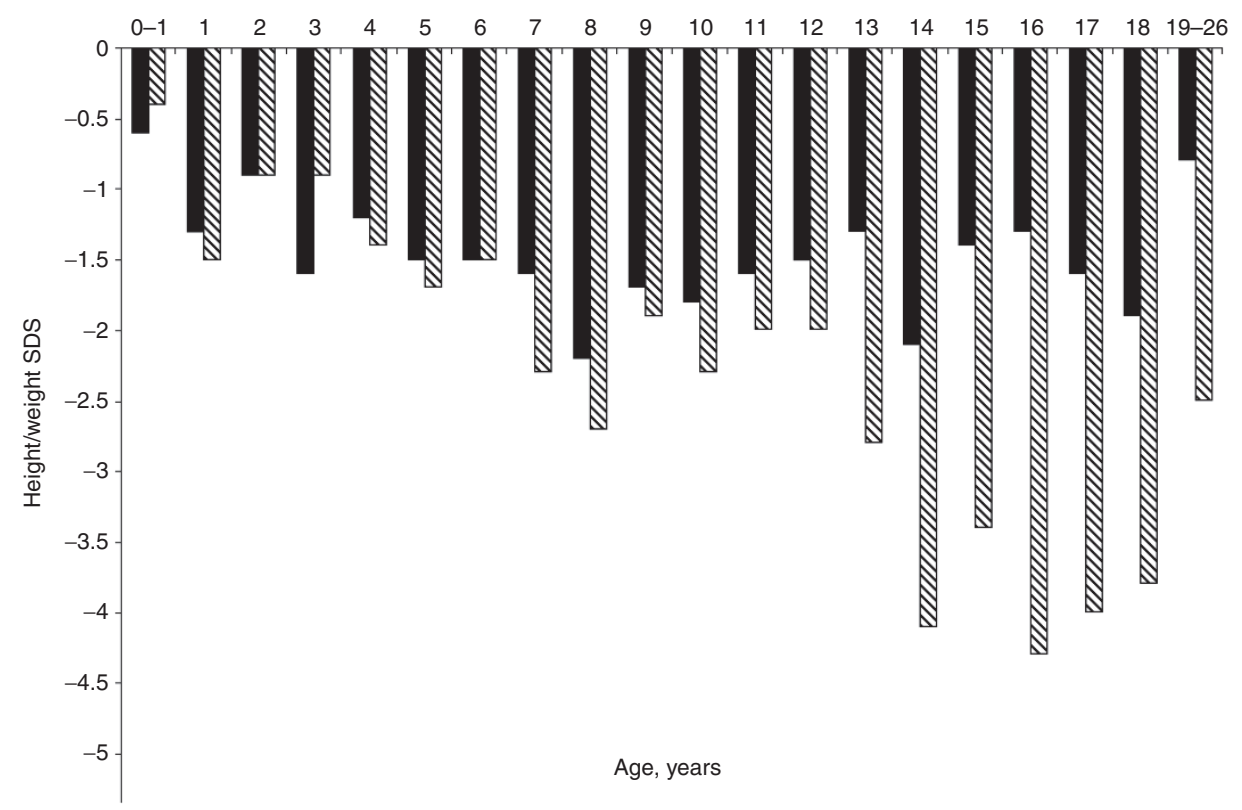

Figure 1. Median height and weight SD score (SDS) measurements according to age. Median height-SDS (black boxes) was subnormal in infancy and did not further decelerate during childhood development. In contrast, median weight-SDS (hatched boxes) paralleled height-SDS during infancy, but progressively decelerated thereafter, especially during the second decade of life. 
levels indicate ovarian failure and it is likely that they will have impairment of pubertal development or amenorrhea.

\section{Glucose Metabolism}

Glucose levels were available in 22 patients and $\mathrm{HbAlc}$ in 29 patients. Two patients (a male and a female) had overt diabetes, while all others had normal glucose and $\mathrm{HbAlc}$ measurements. Both of the diabetic patients were $20 \mathrm{y}$ old at the time they were diagnosed with diabetes, and both had dyslipidemia and abnormal liver function. Neither was obese (BMI 25.7 and $19.8 \mathrm{~kg} / \mathrm{m}^{2}$, respectively). Anti-Gad antibodies were negative in both patients. Anti-insulin antibody was measured in one patient and was negative. One had a prior history of acute lymphocytic leukemia that had been treated with chemotherapy. Both patients were successfully treated with Metformin.

\section{Dyslipidemia}

Lipid profile was available for 25 patients. Mean total cholesterol level was $166 \pm 43 \mathrm{mg} / \mathrm{dl}$, mean HDL was $43 \pm 13 \mathrm{mg} / \mathrm{dl}$, mean LDL was $102 \pm 33 \mathrm{mg} / \mathrm{dl}$, and mean triglyceride level was $127 \pm 70 \mathrm{mg} / \mathrm{dl}$. Five patients had at least one measurement of $\mathrm{LDL}>130 \mathrm{mg} / \mathrm{dl}$, and eight patients has least one triglyceride measurement $>130 \mathrm{mg} / \mathrm{dl}$. Three of the patients with increased LDL also had hypertriglyceridemia.

Table 2. Anthropometric measurements of males vs. females

\begin{tabular}{|c|c|c|c|c|c|}
\hline \multirow{2}{*}{$\begin{array}{l}\text { Age } \\
\text { group }\end{array}$} & \multirow{2}{*}{$\begin{array}{l}N^{\mathrm{a}} \text { (males/ } \\
\text { females) }\end{array}$} & \multicolumn{2}{|c|}{ Height-SDS ${ }^{b}$} & \multicolumn{2}{|c|}{ Weight-SDS $^{\mathrm{b}}$} \\
\hline & & Males & Females & Males & Females \\
\hline $0-5$ & $44 / 46$ & $\begin{array}{c}-1.3 \\
(-1,5 .-1)\end{array}$ & $\begin{array}{c}-1.1 \\
(-2.0,0.1)\end{array}$ & $\begin{array}{c}-1.3 \\
(-1.6,-0.4)\end{array}$ & $\begin{array}{c}-1 \\
(-2.2,-0.5)\end{array}$ \\
\hline $6-10$ & $79 / 49$ & $\begin{array}{c}-1.4 \\
(-2.1,-1.2)\end{array}$ & $\begin{array}{c}-2.2 \\
(-3.0,-1.4)\end{array}$ & $\begin{array}{c}-1.5 \\
(-3.4,-1.2)\end{array}$ & $\begin{array}{c}-2.1 \\
(-3.0,-1.8)\end{array}$ \\
\hline $11-15$ & $63 / 40$ & $\begin{array}{c}-1.4 \\
(-2.2,-0.9)\end{array}$ & $\begin{array}{c}-2.5 \\
(-3.9,-1.1)\end{array}$ & $\begin{array}{c}-2.4 \\
(-4.3,-1.5)\end{array}$ & $\begin{array}{c}-4.4 \\
(-5.9,-2.4)\end{array}$ \\
\hline $16+$ & $46 / 19$ & $\begin{array}{c}-1.1 \\
(-2.1,-0.4)\end{array}$ & $\begin{array}{c}-1.1 \\
(-1.7,-0.4)\end{array}$ & $\begin{array}{c}-3.1 \\
(-5.2,-2.0)\end{array}$ & $\begin{array}{c}-1.3 \\
(-10.1,-1.0)\end{array}$ \\
\hline
\end{tabular}

${ }^{a} n$, number of measurements. ${ }^{b}$ median, interquartile range.

a

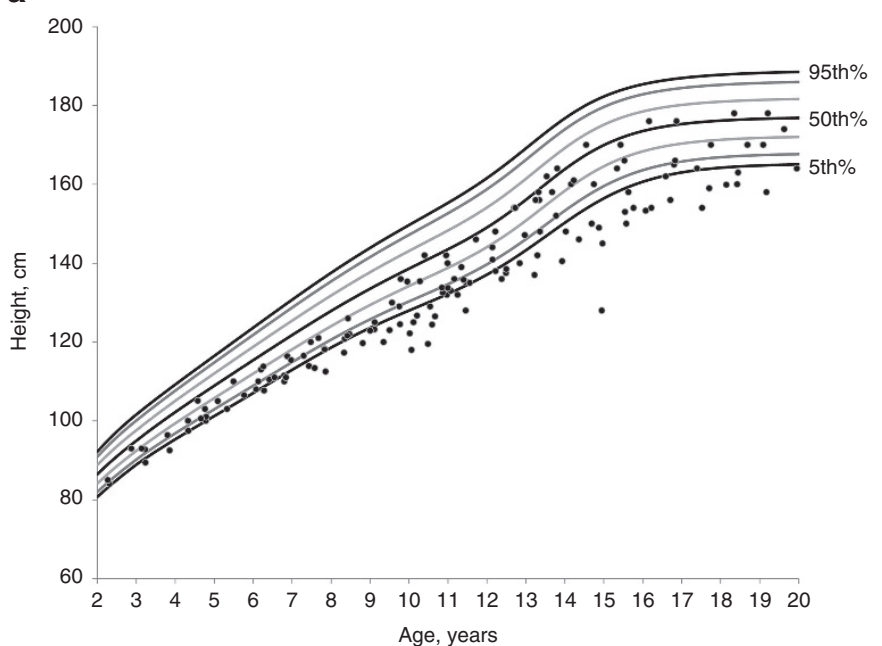

\section{Vitamin D}

Vitamin D levels were available for 23 patients. Mean 25OHD levels were $18.7 \pm 10.9 \mathrm{ng} / \mathrm{ml}$. Twelve patients $(52.2 \%)$ were vitamin D deficient $(<15 \mathrm{ng} / \mathrm{ml})$, and another five $(21.7 \%)$ were vitamin $\mathrm{D}$ insufficient $(15-20 \mathrm{ng} / \mathrm{ml})$. Of the patients with $25 \mathrm{OHD}>20 \mathrm{ng} / \mathrm{ml}(n=6)$, only two patients had 25OHD levels $>32 \mathrm{ng} / \mathrm{ml}$, which are considered optimal by some guidelines (21).

\section{Other Endocrine Measurements}

Thyroid function tests (thyroid-stimulating hormone, FT4) (available in 38 patients), cortisol $(n=31)$ and prolactin levels $(n=32)$ were normal in all evaluated patients.

\section{DISCUSSION}

In the current study, we evaluated endocrine abnormalities and growth patterns in a large cohort of 52 AT patients. Our most prominent findings were growth retardation and impaired body weight. These could be attributed to oropharyngeal dysphagia, chronic pulmonary infection, and impaired glucose metabolism (14). Growth impairment preceded the impairment in weight gain. However, after the age of $4 \mathrm{y}$, weight-SDS steadily decreased, while height-SDS did not further deteriorate.

Growth retardation has been consistently described in patients with AT $(1,4-11,13,14,22)$, usually in small series of patients, lacking longitudinal data or detailed growth patterns. Ersoy et al. (4) showed an association between growth retardation and sinopulmonary infections. Poor weight gain and abnormalities of the GH-IGF-I axis have also been suggested as possible contributors (14).

In the current study, height-SDS was low before clinical onset of disease, and more impaired than weight-SDS in infancy. Thereafter, weight-SDS steadily decreased, while height-SDS did not further deteriorate (Table 1, Figure 1). These findings suggest that growth failure in AT patients is primary, rather than secondary to nutritional impairment or disease severity.

b

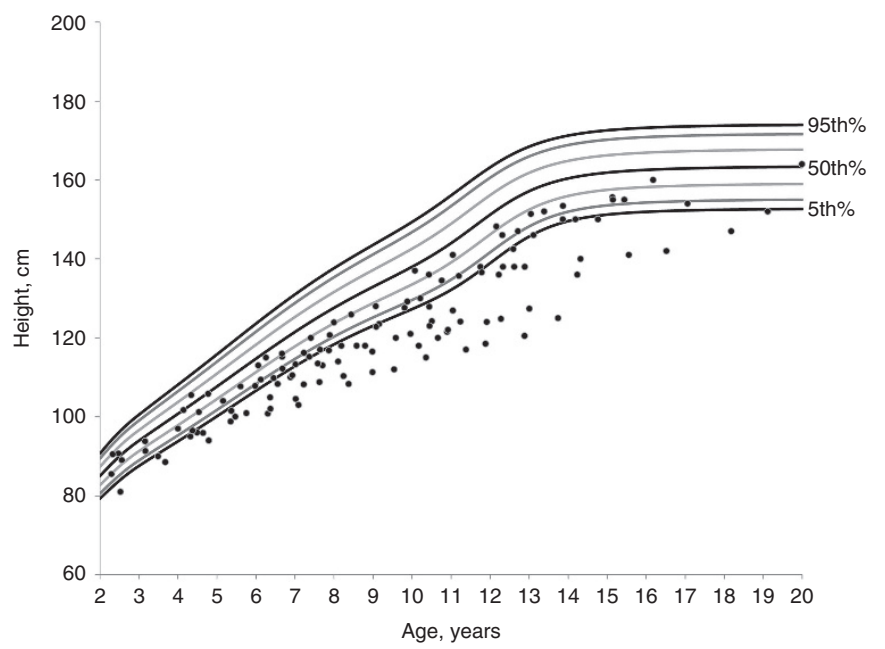

Figure 2. Growth charts of male (2A) and female (2B) AT patients. 


\section{Articles | Nissenkornetal.}

Indeed, there is increasing evidence that growth failure in AT is caused directly by the impairment in ATM gene function. Growth failure is a prominent prenatal and postnatal feature of mutant atm ${ }^{-/}$mice $(23,24)$. Accordingly, human AT fibroblast lines, as well as fibroblasts from the $\mathrm{atm}^{-1-}$ mice, grow slowly, undergo premature senescence, and have high requirements for growth factors $(17,23-25)$. Impaired IGF-I activity may be implicated, as fibroblasts obtained from AT-affected individuals show low levels of IGF-I receptor (IGF-IR) expression and decreased IGF-IR promoter activity (26). Furthermore, Atm may be a modulator of downstream signaling of IGF-I through the Akt/mTOR pathway (27).

Several studies investigated the activity of the GH-IGF-I axis in AT patients, with conflicting results. A recent study by Voss et al. demonstrated severe GH deficiency in 6/10 AT patients with growth retardation (14). The same group has previously reported low IGF-I and IGFBP3 levels in their patients, deteriorating with age (8). In contrast, in three previous studies, $\mathrm{GH}$ stimulation tests were performed on a total of 13 patients showing a normal GH response in all of them $(7,15,16)$, and another study reported increased serum IGF-I levels (28).

Unfortunately, we could not perform GH stimulation tests on any of our patients; however, the pattern of growth curves does not support abnormalities of the GH-IGF-I axis as the main contributor to growth failure in these patients. First, height-SDS seemed to stabilize in early childhood, and did not deteriorate further as would be expected in GH deficiency. Secondly, although mean IGF-I-SDS was low, it did not correlate with height-SDS.

Interestingly, growth retardation seemed to be more prominent in females than in males. This finding could be explained by ovarian failure and consequent compromise of the pubertal growth spurt during adolescence. Still, the impairment in females compared to males, was already evident around the age of $6 y$, before the expected effect of sex hormones on growth velocity (Figure 2, Table 2 ). We did not identify any previous reference regarding this issue in humans, but in the atm $^{-} /^{-}$mice model, females tended to be smaller than male animals (25). This may partially result from absence of the pubertal spurt due to ovarian failure, as shown in this study.

In the current study, we observed sexual dimorphism regarding gonadal function. Among the males, 17/18 assessed patients had normal LH, FSH and all patients older than $13 \mathrm{y}$ had testosterone levels appropriate for their age. In contrast, all female patients older than $10 \mathrm{y}(n=13)$ had elevated levels of $\mathrm{LH}$ and FSH, indicating ovarian failure. Clinically, female patients with high gonadotropin levels presented a spectrum ranging from complete absence of pubertal development to normal sexual development with appearance of menstruation. Only one patient, with retained ATM protein and a mild clinical variant, reported having regular periods for several years.

Regarding AT male patients, several previous studies reported abnormalities of gonadal function, such as cryptorchidism or underdeveloped genitalia $(1,13)$, while others reported normal pubertal development and normal sexual function $(6,12)$. A single study reported increased basal and stimulated LH and FSH levels in a 7-y-old male (15). We did not identify any other documentation of assessment of $\mathrm{LH}$, $\mathrm{FSH}$, and testosterone levels in male AT patients.

Regarding female patients, previous reports, similar to our observation, suggest a spectrum ranging from complete absence of sexual development $(6,9-11)$ to normal development of secondary sexual signs with menstruation $(6,9)$. Intermediate phenotypes were observed as well $(7,12,15)$. Two previous studies $(7,15)$ reported high FSH levels in one patient each. In another study, increased basal and stimulated gonadotropin levels were observed in a 13-y-old female (15). Gonadal abnormalities including hypoplasia with germ cell deficiency or complete absence of the ovaries have been described postmortem $(10,13,29)$.

Gonadal failure has also been observed in the mouse AT model, with lack of mature gametes and a sexual dimorphism similar to our own observation. Male mutant mice have normal development of secondary sexual characteristics, and are capable of mating, but have complete disruption of spermatogenesis and are infertile. Ovaries of mutant females are devoid of primordial and maturing follicles and oocytes-primordial follicles seem to degenerate at the time of prophase of meiosis I in gametogenesis. The uterine lining does not show evidence of proliferation or degeneration, and there is no estrous cycling (24). This may be attributed to Atm control of the number of meiotic double-strand-break (DSB) created by Spo11, important for meiotic recombination during gametogenesis in spermatogonia and priomordial follicle $(23,24,30)$. This mechanism may partially explain the finding of sexual dimorphism: in males, disruption of meiosis would be expected to affect mainly spermatogenesis, while testosterone production by Leydig cells would not be affected. In contrast, in females, hormone production is tightly linked to folliculogenesis, so lack of germ cells would be expected to result in infertility as well as in hormone deficiency. Still, impaired spermatogenesis in males would be expected to be reflected by high FSH levels, which were not observed in our patients. Thus, alternative explanations should be considered as well.

Abnormalities in glucose metabolism progressing with age have also been described in AT patients $(4,6,15,17)$ as well as in atm ${ }^{-/-}$mice (25). Diabetes mellitus was first described by Schlach et al. (16), is characterized by hyperglycemia, hyperinsulinemia, and peripheral insulin resistance, and is rarely associated with glucosuria or ketosis $(6,16)$. It is often associated with liver dysfunction (16) and both appear later in the course of the disease (6). In our cohort, 2/55 patients had overt diabetes, and both had liver dysfunction. All other screened patients had normal glucose and HbA1c measurements.

Regarding the mechanism of diabetes, one study suggested a significant decrease in insulin receptor affinity in monocytes of two AT patients (17). In addition, Atm has been shown to be activated by insulin and to contribute to aspects of insulin action such as phosphorylation of 4EBP1 and, importantly, of Akt. Notably, activation of Akt is central to insulin-stimulated glucose transport in skeletal muscle, which is the primary depot for insulin stimulated clearance of blood glucose (31). 
Atm also appears to regulate insulin functions and glucose homeostasis indirectly through a p53-dependent pathway (32).

Although our diabetic patients were young and nonobese, diabetes-associated autoantibodies were not detected and their diabetes resembled clinically type 2 diabetes. A variant in ATM has been shown to affect the glycemic response of metformin, and adenosine monophosphate-activated protein kinase (AMPK), a mediator of metformin action, may be regulated by ATM (33). Based on this observation, we elected to treat our patients with metformin, with good response.

Several investigators reported histological abnormalities of the pituitary gland $(9,11,13,18,19)$, thyroid $(9)$, and adrenal glands of AT patients $(9,10)$. These findings might be of no clinical consequence, since thyroid function tests, cortisol, and prolactin levels were normal in all assessed patients.

Another major finding in the present study was suboptimal $25 \mathrm{OHD}$ level in $73.9 \%$ of the assessed patients. We could not assess bone density on our patients, since these evaluations require exposure to ionizing radiation. However, disease-related falls, mobility restrictions, and wheelchair-dependency in later disease stages may compromise bone structure and density of AT patients, and predispose them to fractures. Indeed, $\mathrm{atm}^{-/}$ mice show reduced bone mass, attributed to hypogonadism as well as to a direct effect of atm on osteoblast differentiation and impaired IGF-I signaling $(34,35)$. In this regard, maintenance of adequate $25 \mathrm{OHD}$ levels is considered essential in the treatment of decreased bone density in children and adolescents (36). Moreover, a growing body of evidence suggests an important role for vitamin $\mathrm{D}$ in cancer prevention, morbidity and mortality (37). Given the high risk for malignancy in AT patients, maintenance of adequate 25OHD levels seems prudent.

Being a retrospective study based on extraction of data compiled in the medical charts over many years, our study has several limitations. Some patients were lost to follow up and could not be recalled; as well, many of our patients were deceased at the time of data collection. Consequently, some data were missing. Secondly, because the number and timing of growth measurements were different for each patient, it was not possible to perform statistical analysis on these data. Some clinical investigations, as growth hormone levels or bone density studies could not be obtained. However, to our best knowledge, this is the largest series focusing on endocrine abnormalities in AT patients, providing data previously not described regarding growth patterns, sex hormone levels, and vitamin D levels.

In conclusion, our findings suggest that growth retardation is common in AT patients, and that it is a primary feature of the disease, directly associated with the ATM mutation. Moreover, IGF-I levels were subnormal in the majority of our patients. Since IGF-I deficiency might contribute to the progression of neurodegeneration, immunodeficiency and lung failure, it has been suggested that treatment with growth factors may be a beneficial therapeutic option for AT patients (14). Still, these potential benefits should be balanced against concerns regarding a possible causal role of GH treatment in malignancy $(38,39)$. Sex hormone replacement therapy may need to be considered for adolescent females in order to support optimal linear growth, development of secondary sexual signs, and accrual of bone mass. Vitamin D deficiency was common in our cohort and given the implications for bone health and possibly for propensity to malignancy, should be monitored and treated with supplements.

\section{METHODS}

\section{Patients}

We performed a retrospective cross-sectional study on all 55 patients followed at the multidisciplinary AT clinic at the Edmond and Lilly Safra Children's Hospital, Sheba Medical Center, a national referral center for all AT patients in Israel. General demographic and phenotypic data, anthropometric measurements, and pertinent laboratory data were extracted from the medical charts. Three patients were excluded as they had no relevant laboratory or anthropometric measurements.

AT was diagnosed according to typical clinical findings plus one of the following: (i) a proven mutation in the ATM gene, (ii) deficient ATM protein proven by western blotting, (iii) positive linkage to ATM gene, (iv) elevated $\alpha$-fetoprotein, cerebellar atrophy on MRI, and immune deficiency with or without abnormal chromosomal breakage $(40,41)$.

The study was approved by the Institutional review committee at the Sheba Medical Center. (IRB \# SMC-14-1271). Subject/parental informed consent was not required since the data was acquired from the chart while protecting the anonymity of the subject.

\section{Anthropometric Measurements}

Serial height and weight measurements were obtained from the patients' charts, and BMI was calculated based on the formula: weight $(\mathrm{kg}) /$ height $(\mathrm{m})^{2}$. Height, weight, and BMI SD scores were calculated using age and gender-specific growth data (based on the Centers for Disease Control and Prevention's Year 2000 Growth Charts) (www. cdc.gov/growthcharts). These data have been found adequate for assessing Israeli children (42). Recumbent height (length) was used for children younger than 2 y. For wheel-chair bound patients, arm span was measured and used as a surrogate for height.

\section{Laboratory Measurements}

Hormonal evaluation included: thyroid-stimulating hormone, free T4 (FT4), cortisol, IGF-I, FSH, LH, estradiol/testosterone, and prolactin. Blood samples were obtained between 07:00 and 09:00 am after an overnight fast. IGF-I levels were transformed to natural logarithm (ln) in order to achieve normal distribution, and standard deviation scores (IGF-I-SDS) for each subject were calculated as explained elsewhere (43).

\section{Definitions}

Diabetes was defined as fasting glucose level $\geq 126 \mathrm{mg} / \mathrm{dl}$. Dyslipidemia was defined as LDL $>130 \mathrm{mg} / \mathrm{dl}$ or triglycerides $>150 \mathrm{mg} / \mathrm{dl}$ (44). The criteria used to determine vitamin D status were: 25 -hydroxy vitamin D (25OHD) levels $>20 \mathrm{ng} / \mathrm{ml}=$ sufficiency, $15-20 \mathrm{ng} / \mathrm{ml}=$ insufficiency, $<15 \mathrm{ng} / \mathrm{ml}=$ deficiency (45). Since a level of $32 \mathrm{ng} / \mathrm{ml}$ has been suggested as the lower limit of normal for $25 \mathrm{OHD}$ levels by some authorities $(21,45)$, data using this cutoff is also presented.

\section{Data Analysis}

Statistical analyses were performed using SAS version 9.2 (SAS institute, Cary, NC). Descriptive statistics are presented as number (percentages) and mean values \pm SD or median and interquartile ranges. Correlations between IGF-I-SDS, height-SDS, weight-SDS, and BMI-SDS were described using the Pearson correlation coefficient. When several laboratory measurements were available for the same patient, the last available measurement was used. When more than one anthropometric measurement was available for the same age-year for the same patient, the average of these measurements was used.

\section{STATEMENT OF FINANCIAL SUPPORT}

No grant or funding was received for supporting this study.

Disclosure: None of the authors have any disclosures or conflict of interest to declare. 


\section{Articles $\quad$ Nissenkorn et al.}

\section{REFERENCES}

1. Boder E, Sedgwick RP. Ataxia-telangiectasia; a familial syndrome of progressive cerebellar ataxia, oculocutaneous telangiectasia and frequent pulmonary infection. Pediatrics 1958;21:526-54.

2. Chun HH, Gatti RA. Ataxia-telangiectasia, an evolving phenotype. DNA Repair (Amst) 2004;3:1187-96.

3. Savitsky K, Bar-Shira A, Gilad S, et al. A single ataxia telangiectasia gene with a product similar to PI-3 kinase. Science 1995;268:1749-53.

4. Ersoy F, Berkel AI, Sanal O, Oktay H. Twenty-year follow-up of 160 patients with ataxia-telangiectasia. Turk J Pediatr 1991;33:205-15.

5. Peterson RD, Cooper MD, Good RA. Lymphoid tissue abnormalities associated with ataxia-telangiectasia. Am J Med 1966;41:342-59.

6. McFarlin DE, Strober W, Waldmann TA. Ataxia-telangiectasia. Medicine (Baltimore) 1972;51:281-314.

7. Ammann AJ, Duquesnoy RJ, Good RA. Endocrinological studies in ataxiatelangiectasia and other immunological deficiency diseases. Clin Exp Immunol 1970;6:587-95.

8. Schubert R, Reichenbach J, Zielen S. Growth factor deficiency in patients with ataxia telangiectasia. Clin Exp Immunol 2005;140:517-9.

9. Boder E. Ataxia-telangiectasia: some historic, clinical and pathologic observations. Birth Defects Orig Artic Ser 1975;11:255-70.

10. Dunn HG, Meuwissen H, Livingstone CS, Pump KK. Ataxia-telangiectasia. Can Med Assoc J 1964;91:1106-18.

11. Solitare GB, Lopez VF. Louis-bar's syndrome (ataxia-telangiectasia). Neuropathologic observations. Neurology 1967;17:23-31.

12. Woods CG, Taylor AM. Ataxia telangiectasia in the British Isles: the clinical and laboratory features of 70 affected individuals. Q J Med 1992;82: 169-79.

13. Strich SJ. Pathological findings in three cases of ataxia-telangiectasia. J Neurol Neurosurg Psychiatry 1966;29:489-99.

14. Voss S, Pietzner J, Hoche F, et al. Growth retardation and growth hormone deficiency in patients with Ataxia telangiectasia. Growth Factors 2014;32:123-9.

15. Zadik Z, Levin S, Prager-Lewin R, Laron Z. Gonadal dysfunction in patients with ataxia telangiectasia. Acta Paediatr Scand 1978;67:477-9.

16. Schalch DS, McFarlin DE, Barlow MH. An unusual form of diabetes mellitus in ataxia telangiectasia. N Engl J Med 1970;282:1396-402.

17. Bar RS, Levis WR, Rechler MM, et al. Extreme insulin resistance in ataxia telangiectasia: defect in affinity of insulin receptors. N Engl J Med 1978;298:1164-71.

18. Bowden DH, Danis PG, Sommers SC. Ataxia-telangiectasia. A case with lesions of ovaries and adenohypophysis. J Neuropathol Exp Neurol 1963;22:549-54.

19. Kovacs K, Giannini C, Scheithauer BW, Stefaneanu L, Lloyd RV, Horvath E. Pituitary changes in ataxia-telangiectasia syndrome: an immunocytochemical, in situ hybridization, and DNA cytometric study of three cases. Endocr Pathol 1997;8:195-203.

20. Bielorai B, Fisher T, Waldman D, et al. Acute lymphoblastic leukemia in early childhood as the presenting sign of ataxia-telangiectasia variant. Pediatr Hematol Oncol 2013;30:574-82.

21. Holick MF, Binkley NC, Bischoff-Ferrari HA, et al.; Endocrine Society. Evaluation, treatment, and prevention of vitamin D deficiency: an Endocrine Society clinical practice guideline. J Clin Endocrinol Metab 2011;96:1911-30.

22. Li A, Swift M. Mutations at the ataxia-telangiectasia locus and clinical phenotypes of A-T patients. Am J Med Genet 2000;92:170-7.

23. Xu Y, Ashley T, Brainerd EE, Bronson RT, Meyn MS, Baltimore D. Targeted disruption of ATM leads to growth retardation, chromosomal fragmentation during meiosis, immune defects, and thymic lymphoma. Genes Dev 1996;10:2411-22.
24. Barlow C, Hirotsune S, Paylor R, et al. Atm-deficient mice: a paradigm of ataxia telangiectasia. Cell 1996;86:159-71.

25. Miles PD, Treuner K, Latronica M, Olefsky JM, Barlow C. Impaired insulin secretion in a mouse model of ataxia telangiectasia. Am J Physiol Endocrinol Metab 2007;293:E70-4.

26. Peretz S, Jensen R, Baserga R, Glazer PM. ATM-dependent expression of the insulin-like growth factor-I receptor in a pathway regulating radiation response. Proc Natl Acad Sci USA 2001;98:1676-81.

27. Ching JK, Luebbert SH, Collins RL 4th, et al. Ataxia telangiectasia mutated impacts insulin-like growth factor 1 signalling in skeletal muscle. Exp Physiol 2013;98:526-35.

28. Busiguina S, Fernandez AM, Barrios V, et al. Neurodegeneration is associated to changes in serum insulin-like growth factors. Neurobiol Dis 2000;7(6 Pt B):657-65.

29. Miller ME, Chatten J. Ovarian changes in ataxia telangiectasia. Acta Paediatr Scand 1967;56:559-61.

30. Lange J, Pan J, Cole F, Thelen MP, Jasin M, Keeney S. ATM controls meiotic double-strand-break formation. Nature 2011;479:237-40.

31. Ching JK, Spears LD, Armon JL, et al. Impaired insulin-stimulated glucose transport in ATM-deficient mouse skeletal muscle. Appl Physiol Nutr Metab 2013;38:589-96.

32. Ambrose M, Gatti RA. Pathogenesis of ataxia-telangiectasia: the next generation of ATM functions. Blood 2013;121:4036-45.

33. Zhou K, Bellenguez C, Spencer CC, et al. Common variants near ATM are associated with glycemic response to metformin in type 2 diabetes. Nat Genet 2011;43:117-20.

34. Rasheed N, Wang X, Niu QT, Yeh J, Li B. Atm-deficient mice: an osteoporosis model with defective osteoblast differentiation and increased osteoclastogenesis. Hum Mol Genet 2006;15:1938-48.

35. Hishiya A, Ito M, Aburatani H, Motoyama N, Ikeda K, Watanabe K. Ataxia telangiectasia mutated (Atm) knockout mice as a model of osteopenia due to impaired bone formation. Bone 2005;37:497-503.

36. Bachrach LK, Ward LM. Clinical review 1: Bisphosphonate use in childhood osteoporosis. J Clin Endocrinol Metab 2009;94:400-9.

37. Li M, Chen P, Li J, Chu R, Xie D, Wang H. Review: the impacts of circulating 25-hydroxyvitamin $\mathrm{D}$ levels on cancer patient outcomes: a systematic review and meta-analysis. J Clin Endocrinol Metab 2014;99:2327-36.

38. Jenkins PJ, Mukherjee A, Shalet SM. Does growth hormone cause cancer? Clin Endocrinol (Oxf) 2006;64:115-21.

39. Pollak M. Insulin and insulin-like growth factor signalling in neoplasia. Nat Rev Cancer 2008;8:915-28.

40. Nissenkorn A, Hassin-Baer S, Lerman SF, Levi YB, Tzadok M, Ben-Zeev B. Movement disorder in ataxia-telangiectasia: treatment with amantadine sulfate. J Child Neurol 2013;28:155-60.

41. Nissenkorn A, Levi YB, Vilozni D, et al. Neurologic presentation in children with ataxia-telangiectasia: is small head circumference a hallmark of the disease? J Pediatr 2011;159:466-471.e1.

42. Goldstein A, Haelyon U, Krolik E, Sack J. Comparison of body weight and height of Israeli schoolchildren with the Tanner and Centers for Disease Control and Prevention growth charts. Pediatrics 2001;108:E108.

43. Ranke MB, Schweizer R, Elmlinger MW, et al. Relevance of IGF-I, IGFBP3 , and IGFBP-2 measurements during GH treatment of GH-deficient and non-GH-deficient children and adolescents. Horm Res 2001;55:115-24.

44. Expert panel on integrated guidelines for cardiovascular health and risk reduction in children and adolescents: summary report. Pediatrics 2011;128 Suppl 5:S213-56.

45. Misra M, Pacaud D, Petryk A, Collett-Solberg PF, Kappy M; Drug and Therapeutics Committee of the Lawson Wilkins Pediatric Endocrine Society. Vitamin D deficiency in children and its management: review of current knowledge and recommendations. Pediatrics 2008;122:398-417. 